\title{
Safety and Effectiveness of Endoscopic Savary-Gillaard Bougies Dilation in Moroccan Plummer-Vinson Syndrome Patients
}

\author{
Mouna Salihoun, Nawal Kabbaj, Ferdaous Raissouni, Zakia Chaoui, \\ Acharki Mohamed, and Amrani Naima
}

EFD-Hepatogastroenterology Unit, Ibn Sina Hospital, Mohammed V University, Rabat, Morocco

Correspondence should be addressed to Mouna Salihoun; mounasalihoun@hotmail.com

Received 21 June 2012; Accepted 16 September 2012

Academic Editors: G. Larciprete and J. Vyankandondera

Copyright (c) 2013 Mouna Salihoun et al. This is an open access article distributed under the Creative Commons Attribution License, which permits unrestricted use, distribution, and reproduction in any medium, provided the original work is properly cited.

\begin{abstract}
The authors aimed to better define the clinical, biological, radiological, endoscopic, and evolutionary characteristics of patients presenting with Plummer-Vinson syndrome after endoscopic dilation and medical treatment in this study. There were 41 cases of Plummer-Vinson syndrome listed. All these patients presented dysphagia associated to anemia, and all have benefited endoscopic dilation and iron supplementation with a good clinical and biological course in 100\% of cases. The Plummer-Vinson syndrome is a rare entity. The treatment, based essentially on endoscopic dilations, is effective and safe.
\end{abstract}

\section{Background}

Plummer-Vinson syndrome is characterized by the classic triad cervical dysphagia, iron deficiency anemia, and upper esophageal web or webs. While this syndrome is known as Plummer-Vinson syndrome in the United States, it is known as Paterson-Brown Kelly syndrome in the United Kingdom [1, 2]. It has been known since the beginning of the 20th century. Plummer established the syndrome for the first time in 1912 and has published 21 cases with diffuse dilation of the esophagus and spasm of the upper esophagus without anatomic stenosis [1]. Then Vinson published another case with angulation of the esophagus [3]. Paterson and Kelly described for the first time the characteristic clinical signs of the syndrome $[2,4]$.

Even though the syndrome is very rare nowadays, its recognition is important because it identifies a group of patients at increased risk of squamous cell carcinoma of the pharynx and the esophagus [5].

The purpose of our study was to retrospectively evaluate the effectiveness of Savary-Gillard bougies dilation for the treatment of Plummer Vinson syndrome.

\section{Material and Methods}

We retrospectively analyzed 62 bougienage dilations (BD) with Savary-Gilliard bougies in 41 patients for PlummerVinson syndrome during a period 2005-2010. The study included 36 women and 5 men with a median age 39 years ranging from 18 to 62 at the time of the initial dilation. All patients underwent a barium esophagography before performing bougies dilation to evaluate the stricture location (Figures 1 and 2).

The dilations were performed in an ambulatory environment with varying intervals between sessions (Figure 3 ) by several endoscopists. The procedure was performed with the patient fasting for at least 8 hours, under sedation with intravenous propofol without fluoroscopic guidance. We used a flexible guide wire, inserted through the stricture under endoscopic vision, on which the Savary-Gilliard bougies were passed, consisting of soft polyvinyl material, with a gradual increase in size. The diameter of the bougies was individualized according to the degree of stenosis presented.

In the absence of procedural complications such as an esophageal perforation, patients were allowed a soft food diet and were encouraged to resume a regular diet the day following the procedure. 


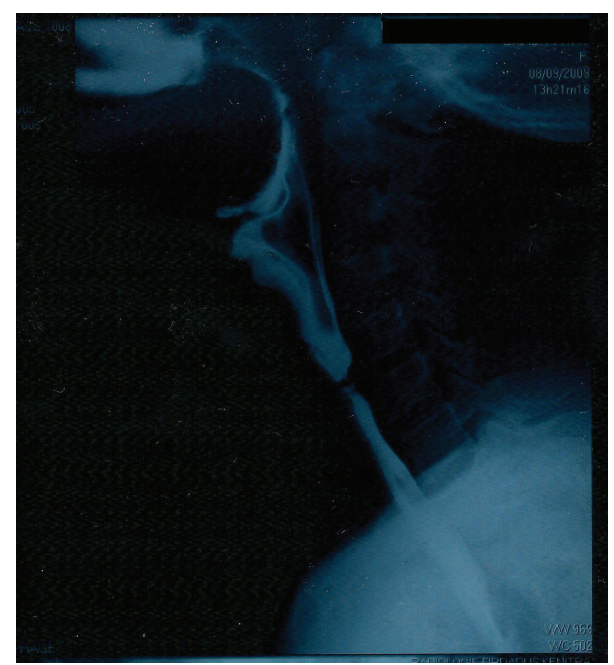

FIGURE 1: Barium swallow showing oesophageal web.

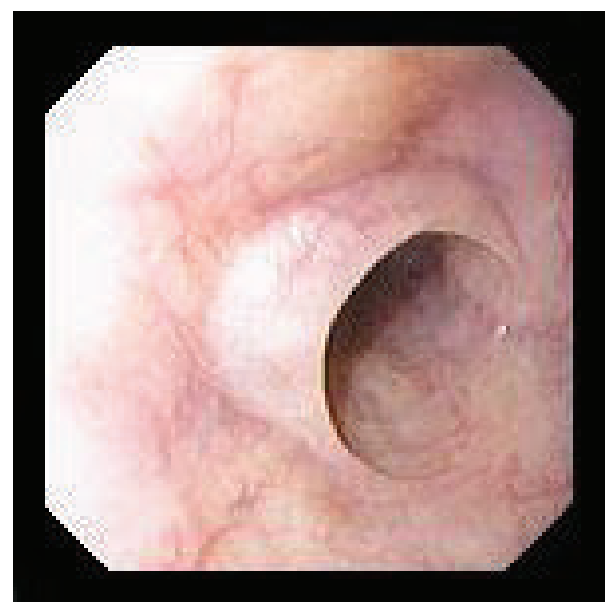

FIgURE 2: Endoscopic view of oesophageal web.

We defined temporary success as dysphagia relief for at least one month after the BD session and long-term success as dysphagia relief for at least 12 months after the last BD.

\section{Results}

All patients presented painless and intermittent dysphagia limited to solids and associated with weight loss in 5 patients. Iron deficiency anemia was present in $100 \%$ patient with a mean value of hemoglobin of $9.2 \mathrm{~g} / \mathrm{dL}$ and low ferritin during a period from 1 to 20 years. The esophagoscopy confirmed the presence of a web in the subcricoid region in 29 patients and in the cervical oesophagus in 12 patients.

A total of 62 dilatation sessions were performed in 41 patients, with 1 to 3 sessions per patient (median: 2 sessions per patient). Initial bougienage dilation was performed using bougies of 7 to $8 \mathrm{~mm}$ in diameter in 13 patients with severe stricture, whereas in 28 patients, we used 9 to $10 \mathrm{~mm}$ in diameter. The maximum bougies diameter of the last session ranged from 13 to $15 \mathrm{~mm}$.

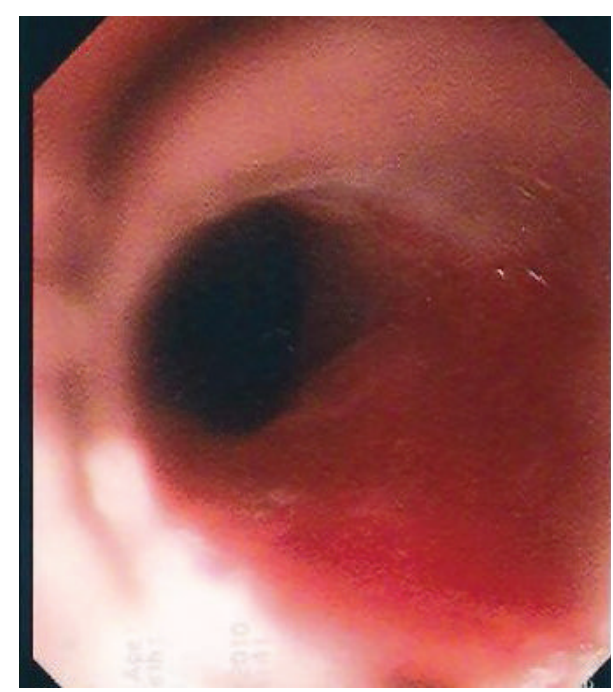

Figure 3: Endoscopic view after dilation of web.

2 patients presented double webs diagnosed after dilatation in 18 and $22 \mathrm{~cm}$ of dentistry arcade, respectively. 3 patients have associated disorder as celiac disease in 1 patient, oesophageal varices in 1 patient, and gastric carcinoid tumor in 1 patient. Esophageal biopsies are performed routinely after dilation to eliminate neoplasia.

There was no complication as bleeding or perforation after dilation session and endoscope passed through the esophagus easily. Repeat dilatation was performed in 3 patients for severe stricture. All patients were treated with oral iron and hemoglobin control after 3 months showed correction of anemia. The remaining web disappears during upper endoscopy follow-up and there was no recurrence or malignant degeneration during a mean followup period of 31.5 months (range 3-60 months).

\section{Discussion}

The exact data about incidence and prevalence of the syndrome are not available. In the first half of the 20th century Plummer-Vinson syndrome seemed to be common in the Scandinavian population, especially in middle-aged women, but it is extremely rare today with only case reports being published in the literature in recent years [6].

The decline in reports and incidence of the syndrome may be related to the improvement in nutritional status and better treatment of iron deficiency [7]. In Africa, where both iron deficiency and malnutrition are common, the syndrome is very rare. However in North Africa, many Plummer-Vinson syndrome cases are still being reported [8]. In Morocco, although the prevalence of anemia is high around $30 \%$, Plummer-Vinson syndrome is rare This attests that it takes several factors combined with iron-deficiency anemia.

In our series, most patients (85\%) are women aged over 40 years and have an iron-deficiency anemia. These data are concordant to the literature. 
The pathogenesis of the syndrome remains unclear, but possible etiopathogenetic mechanisms include iron deficiency, genetic predisposition, or autoimmune disorder. It is reported that iron deficiency leads to the reduction of iron-dependent oxidative enzymes, which results in gradual degradation of muscles of the pharynx. As a result, mucosal atrophy leads to development of webs [9]. It was reported that, in a patient with Plummer-Vinson syndrome, iron deficiency caused esophageal motility decrease; new motility studies showed normal amplitude of contraction after iron therapy [10]. But population studies do not confirm the etiologic association between iron deficiency and web formation. Furthermore, this theory does not explain the presence of these webs exclusively in the upper part of the esophagus $[9,11]$.

Other etiologic factors including malnutrition, genetic predisposition, or even autoimmune processes have been proposed. The latter is based on the association between Plummer-Vinson syndrome and certain autoimmune disorders such as celiac disease, thyroid disease, and rheumatoid arthritis [12-14]. It is proposed that these diseases may cause iron deficiency and then result in webs in upper esophageal $[14,15]$. In the present study, one patient had coeliaque disease and the other one oesophageal varices confirming that the anemia caused by these diseases may be causing the plummer vinson syndrome but cannot explain occurrence of the webs in other cases.

The first step in the management of Plummer-Vinson syndrome is to clarify the cause of iron deficiency in order to exclude active hemorrhage, malignancy, or celiac disease. Plummer-Vinson syndrome can be treated easily and effectively with iron supplementation alone [16]. However, in case of significant obstruction of the esophageal lumen by esophageal web and persistent dysphagia despite iron supplementation, rupture and dilation of the web should be performed by mechanical dilation. Bougienage dilation is preferred in previous reports but successful balloon dilation has been described $[17,18]$. In our series, bougienage dilation has been successful without complications. A new therapeutical option has been described recently using argon plasma coagulation therapy of upper esophageal web in one case of Plummer-Vinson syndrome [19]. This technique needs further investigation using a larger number of patients and long-term follow-up period.

Plummer-Vinson syndrome is known to be associated with upper alimentary tract cancer as oesophagus squamous cell cancer and gastric cancer. Surveillance by upper gastrointestinal endoscopy is recommended every year, even though the effectiveness of this recommendation is not definitively confirmed [16]. Prognosis of the Plummer-Vinson syndrome is excellent as dysphagia and anemia can be treated effectively but it becomes dramatic in case of an associated squamous cell carcinoma of the hypopharynx or upper esophagus.

\section{References}

[1] S. Plummer, "Diffuse dilatation of the esophagus without anatomic stenosis (cardiospasm) A report of ninety-one cases,"
The Journal of the American Medical Association, vol. 58, no. 26, pp. 2013-2015, 1912.

[2] D. R. - Paterson, "A clinical type of dysphagia," The Journal of Laryngology \& Otology, vol. 34, pp. 289-291, 1919.

[3] P. P. Vinson, "A case of cardiospasm with dilatation and angulation of the esophagus," Medical Clinics of North America, vol. 3, pp. 623-627, 1919.

[4] A. B. Kelly, "Spasm at the entrance of the esophagus," Annals of Otology, Rhinology and Laryngology, vol. 34, pp. 285-289, 1919.

[5] M. H. Shamma'a and E. B. Benedict, "Esophageal webs, a report of 58 cases and an attempt at classification," The New England Journal of Medicine, vol. 259, no. 8, pp. 378-384, 1958.

[6] E. L. Wynder, S. Hultberg, F. Jacobsson, and I. J. Bross, "Environmental factors in cancer of the upper alimentary tract. A Swedish study with special reference to Plummer-Vinson (Paterson-Kelly) syndrome," Cancer, vol. 10, pp. 470-482, 1957.

[7] T. S. N. Chen and P. S. Y. Chen, "Rise and fall of the PlummerVinson syndrome," Journal of Gastroenterology and Hepatology, vol. 9, no. 6, pp. 654-658, 1994.

[8] O. Ben Gamra, C. Mbarek, C. Mouna et al., "Plummer Vinson syndrome," Tunisie Medicale, vol. 85, no. 5, pp. 402-404, 2007.

[9] K. Atmatzidis, B. Papaziogas, T. Pavlidis, C. Mirelis, and T. Papaziogas, "Plummer-Vinson syndrome," Diseases of the Esophagus, vol. 16, no. 2, pp. 154-157, 2003.

[10] R. O. Dantas and M. G. Villanova, "Esophageal motility impairment in Plummer-Vinson syndrome. Correction by iron treatment," Digestive Diseases and Sciences, vol. 38, no. 5, pp. 968-971, 1993.

[11] R. O. Dantas, "Iron deficiency and dysphagia," American Journal of Gastroenterology, vol. 94, no. 10, pp. 3072-3073, 1999.

[12] W. Dickey and B. McConnell, "Celiac disease presenting as the Paterson-Brown Kelly (Plummer-Vinson) syndrome," American Journal of Gastroenterology, vol. 94, no. 2, pp. 527-529, 1999.

[13] M. Medrano, "Dysphagia in a patient with rheumatoid arthritis and iron deficiency anemia," MedGenMed, vol. 4, no. 3, p. 10, 2002.

[14] G. K. Makharia, B. Nandi, P. K. Garg, and R. K. Tandon, "Plummer Vinson syndrome: unusual features," Indian Journal of Gastroenterology, vol. 21, no. 2, pp. 74-75, 2002.

[15] D. Maleki and A. J. Cameron, "Plummer-Vinson syndrome associated with chronic blood loss anemia and large diaphragmatic hernia," American Journal of Gastroenterology, vol. 97, no. 1, pp. 190-193, 2002.

[16] R. M. Hoffman and P. E. Jaffe, "Plummer-Vinson syndrome: a case report and literature review," Archives of Internal Medicine, vol. 155, no. 18, pp. 2008-2011, 1995.

[17] D. V. Sreenivas, A. Kumar, K. V. R. Mannar, and G. R. Babu, "Results of savary-gilliard dilatation in the management of cervical web of esophagus," Hepato-Gastroenterology, vol. 49, no. 43, pp. 188-190, 2002.

[18] F. Demirci, M. C. Savaş, N. Kepkep et al., "Plummer-Vinson syndrome and dilation therapy: a report of two cases," Turkish Journal of Gastroenterology, vol. 16, no. 4, pp. 224-227, 2005.

[19] L. C. Pérez, J. G. Morales, C. B. Radigales, and A. C. Ruiz, "Argon plasma coagulation therapy of upper esophageal web in a patient with Plummer-Vinson syndrome: a new therapeutical option," Medicina Clinica, vol. 135, no. 3, pp. 141-142, 2010. 


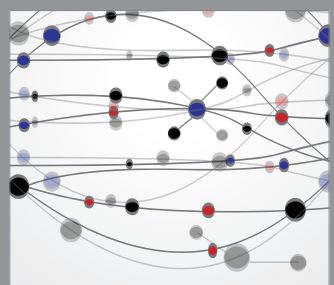

The Scientific World Journal
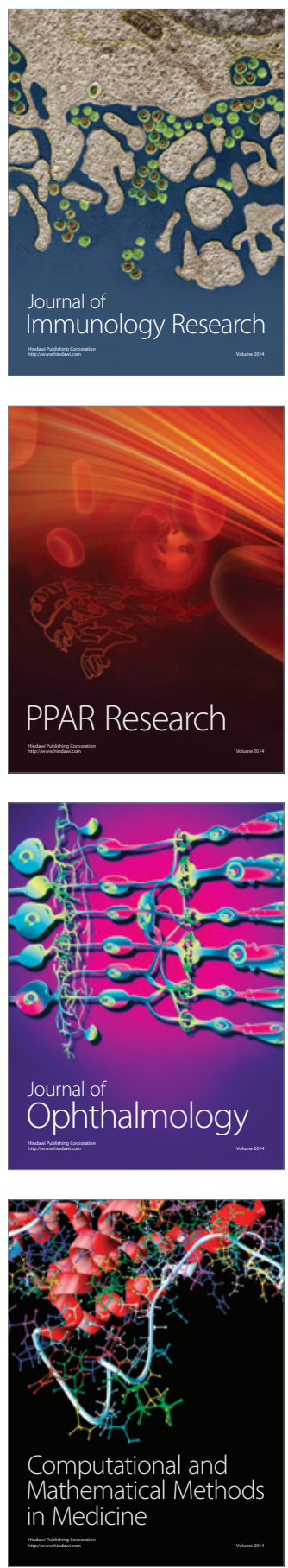

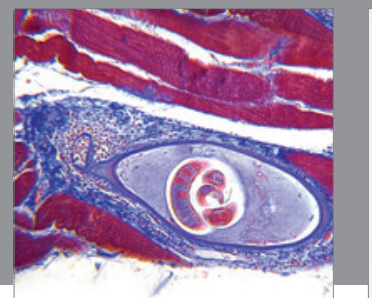

Gastroenterology

Research and Practice
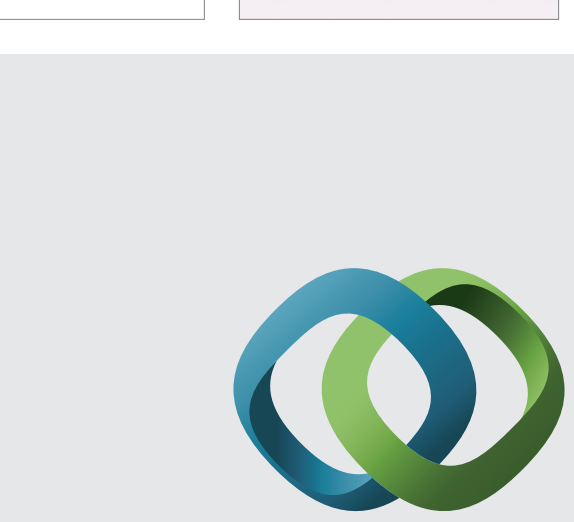

\section{Hindawi}

Submit your manuscripts at

http://www.hindawi.com
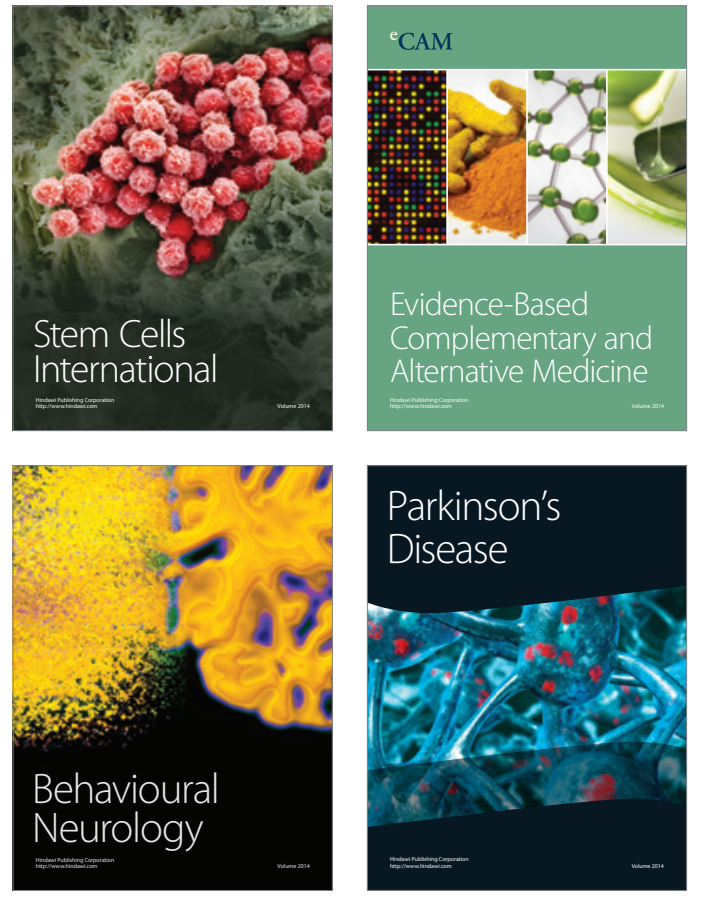
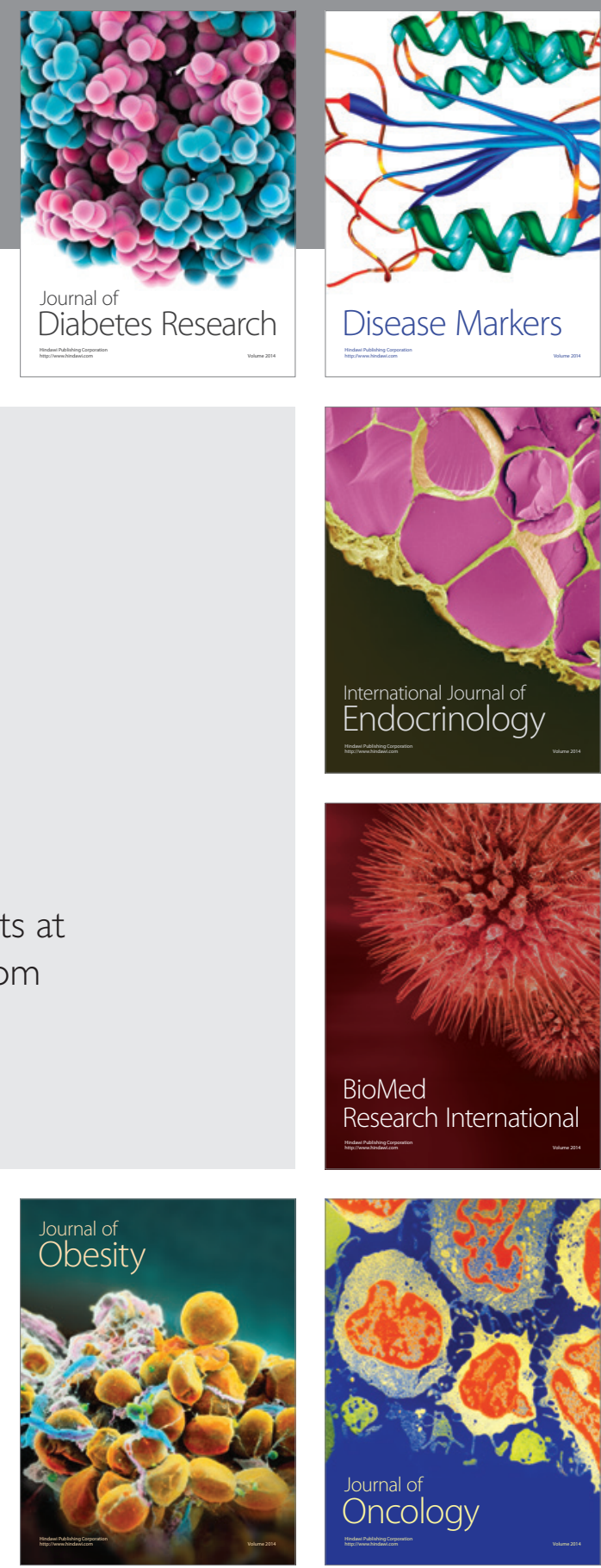

Disease Markers
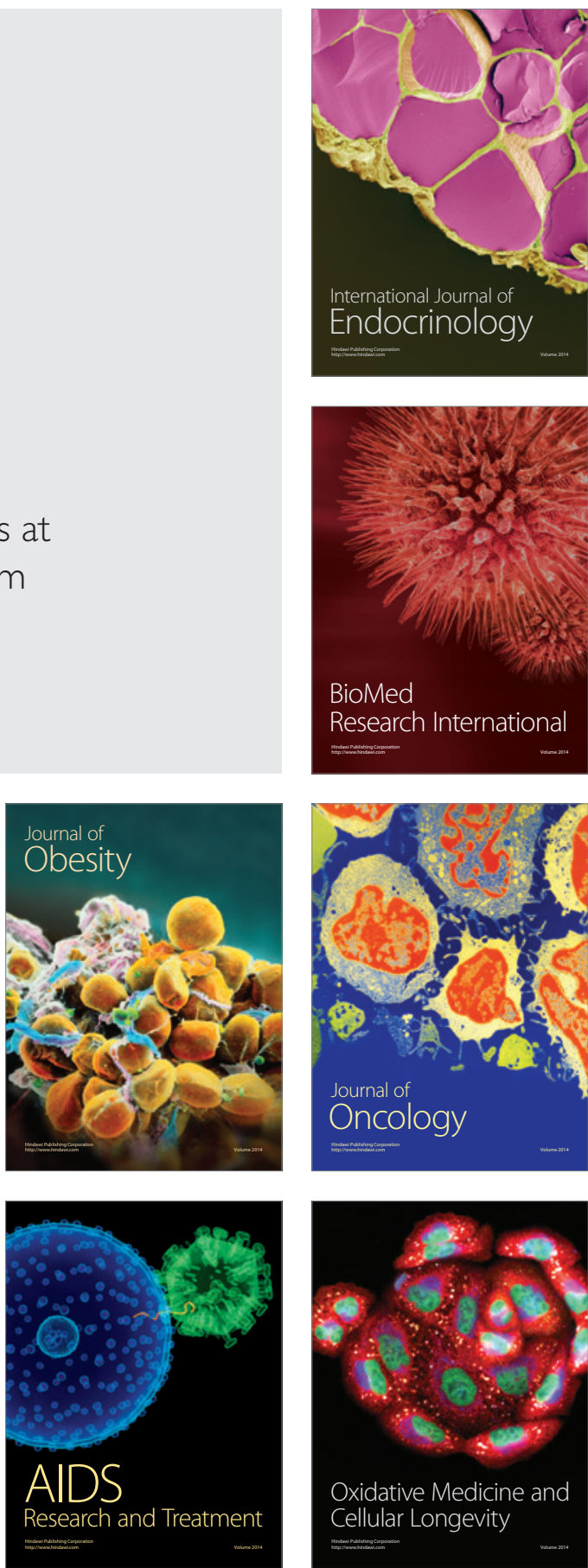